\title{
BMJ Open A priori choice of neuraxial labour analgesia and breastfeeding initiation success: a community-based cohort study in an Italian baby-friendly hospital
}

To cite: Wetzl RG, Delfino $\mathrm{E}$, Peano L, et al. A priori choice of neuraxial labour analgesia and breastfeeding initiation success: a community-based cohort study in an Italian babyfriendly hospital. BMJ Open 2019:9:e025179. doi:10.1136/ bmjopen-2018-025179

- Prepublication history and additional material for this paper are available online. To view these files, please visit the journal online (http://dx.doi. org/10.1136/bmjopen-2018025179).

Received 6 July 2018

Revised 7 January 2019

Accepted 11 January 2019

Check for updates

(C) Author(s) (or their employer(s)) 2019. Re-use permitted under CC BY-NC. No commercial re-use. See rights and permissions. Published by BMJ.

For numbered affiliations see end of article.

Correspondence to Dr Roberto Giorgio Wetzl; robertowetz|@libero.it

\section{ABSTRACT}

Objective To investigate whether the nature of the decision about receiving neuraxial labour analgesia is associated with breastfeeding initiation success (BIS), defined as exclusive breastfeeding until discharge associated with postnatal weight loss $<7 \%$ at 60 hours from birth.

Design Single-centre community-based cohort study. Setting An Italian baby-friendly hospital, from 1 July 2011 to 22 September 2015.

Participants Inclusion criteria: women vaginally delivering singleton cephalic newborns and willing to breastfeed. Exclusion criteria: women who delivered in uterus-dead fetuses, were single or requested but did not receive neuraxial analgesia. Overall, 775 out of the 3628 enrolled women received neuraxial analgesia.

Results Compared with women who tried to cope with labour pain, those who decided a priori to receive neuraxial analgesia had less BIS (planned vaginal birth: 2121/3421 (62.0\%), vs 102/207 (49.3\%; $p<0.001$; risk difference (RD), 12.7\%); actual vaginal birth: 1924/2994 (64.3\%), vs $93 / 189$ (49.2\%; $p<0.001 ; \mathrm{RD}, 15.1 \%))$. Multivariable analyses with antelabour-only confounders confirmed both associations (planned vaginal birth: relative risk (RR), $0.65 ; 95 \% \mathrm{Cl}, 0.48$ to 0.87 ; actual vaginal birth: $\mathrm{RR}, 0.59$; $95 \% \mathrm{Cl}, 0.43$ to 0.80 ). Although women who requested analgesia as a last resort had less BIS than did those successfully coping with labour pain in the bivariable analyses (planned vaginal birth: $1804 / 2853(63.2 \%)$, vs $317 / 568$ (55.8\%; $p=0.001 ; R D, 7.4 \%)$; actual vaginal birth: $1665 / 2546$ (65.4\%), vs $259 / 448$ (57.8\%; $p=0.002$; $\mathrm{RD}, 7.6 \%)$ ), multivariable analyses with either antelabouronly or peripartum confounders did not confirm these associations (planned vaginal birth: $\mathrm{RR}, 0.99 ; 95 \% \mathrm{Cl}, 0.80$ to 1.23 ; actual vaginal birth: $\mathrm{RR}, 0.90 ; 95 \% \mathrm{Cl}, 0.69$ to 1.16).

Conclusions Compared with trying to cope with labour pain, a priori choice of neuraxial analgesia is negatively associated with BIS. Conversely, compared with having successfully coped with pain, requesting neuraxial analgesia as a last resort is not negatively associated with BIS.

\section{Strengths and limitations of this study}

- The study enrolled a large and almost unselected population of mother-baby dyads due to the limited exclusion criteria.

- The comparison of groups is meaningful because physiologic birth was the true reference point.

- The outcome measure is robust because it included an index of the newborn's nutritional status at discharge.

- The generalisability of the findings may be limited due to the observational, single-centre design.

- The baby-friendly designation of the hospital may introduce a possible selection bias.

\section{INTRODUCTION}

A growing body of evidence now supports the consideration of breastfeeding as the normative standard for infant feeding. ${ }^{1-11}$ In the past, the risk factors for breastfeeding failure have been investigated extensively to steer policies and interventions aimed at promoting breastfeeding success. Among the several medical interventions that could affect breastfeeding success, the role of neuraxial labour analgesia has been investigated thoroughly. Several studies have found that neuraxial labour analgesia can negatively impact either the initiation or duration of exclusive breastfeeding. ${ }^{12-18}$ Although some reviewers have also quoted reassuring studies, to date, consistent results have not been reported. ${ }^{19} 20$ The recent release of the "Intrapartum Care for a Positive Childbirth Experience' guidelines by the $\mathrm{WHO}^{21}$ pushes for an in-depth analysis of the relationship between neuraxial labour analgesia and breastfeeding. Indeed, these guidelines recommend pharmacological labour analgesia (either 
neuraxial analgesia or parenteral opioid administration) 'for healthy pregnant women requesting pain relief during labour, depending on a woman's preferences'. Moreover, these guidelines underline that women who expressed an 'a priori desire for analgesia' to experience a pain-free labour may be different from those who only 'requested analgesia as a last resort' when the pain level was overwhelming.

To the best of our knowledge, the association between the nature of the decision about receiving neuraxial labour analgesia and breastfeeding success has not yet been investigated. Thus, we aimed to investigate whether the decision about receiving neuraxial labour analgesia, either a priori or as a last resort, was associated with breastfeeding initiation success (BIS) at discharge from a baby-friendly hospital. Specifically, we aimed to test two hypotheses. First, among women trying to deliver vaginally, we hypothesised that women who choose analgesia a priori have a lower BIS than do those who try to cope with labour pain. Second, among women who try to cope with labour pain, we hypothesised that those who request analgesia only as a last resort have similar BIS as those who successfully cope with labour pain.

\section{METHODS}

This manuscript adheres to the Strengthening the Reporting of Observational Studies in Epidemiology guidelines. The Aosta Valley community comprises 125 000 inhabitants, and the Parini Regional Hospital is the only available facility in the county. There are 1200 deliveries each year at this hospital, and since 2010, it has been repeatedly designated by Unicef as a baby-friendly hospital. All women who delivered at the facility between 1 July 2011 and 22 September 2015 were screened for eligibility. All women who planned to give birth vaginally to a singleton cephalic newborn and expressed the desire to breastfeed the baby were included in the study. Women who delivered an in uterus-dead fetus, who were currently single or who requested neuraxial analgesia but did not receive it due to technical difficulties were excluded. Single mothers were excluded because only a few of the potential participants were single and the analyses included several confounders that were relevant to both parents as a couple.

The study predictors were the a priori choice for analgesia and the request for analgesia as a last resort. Women were considered as choosing neuraxial labour analgesia a priori if they chose to receive the analgesia by themselves, and requested it on arrival at the delivery room without considering alternative means of pain relief offered by the facility's midwives. On the other hand, women were considered as requesting analgesia as a last resort if they requested it later during labour progression, or only after considering other techniques offered by the facility's midwives (postures, massage, water immersion, etc). In the latter case, the trigger for the request was an overwhelming level of pain or an unmanageable sense of control over the labour or both, and the woman's decision was shared and supported by healthcare professionals. The decision about receiving neuraxial analgesia was first collected by the attending midwife when the women arrived at the delivery room (ie, when the active phase of labour was beginning or when labour would be induced with oxytocin). The need of labour induction was not considered a routine indication for neuraxial analgesia implementation or proactive epidural catheter placement. Accordingly, the woman's decision about receiving analgesia was collected by the duty gynaecologist when the woman signed the informed consent for the induction of labour and it was reported by the attending midwife in the delivery room. The women were then divided into two groups, those trying to cope with labour pain on their own (trying to cope group), and those who chose to receive analgesia a priori (a priori choice group). Thereafter, should women in the trying to cope group give up and demand analgesia, they were classified as requesting analgesia as a last resort (last resort group). In contrast, women who did not require neuraxial labour analgesia were categorised as having successfully coped with the pain (successful coping group).

Neuraxial labour analgesia was administered by the duty anaesthetist using the same technique in the a priori choice and last resort groups. The analgesia was either a combined spinal-epidural or a classic epidural, and in either case, a low-dose, high-volume mixture of ropivacaine and sufentanil was administered as intermittent on-demand boluses by the duty anaesthetist to pursue a verbal rating pain score from 4 to 6 out of 10 according to the woman's wishes.

The study endpoint was BIS, as collected by the attending paediatrician at hospital discharge. BIS was defined as exclusive breastfeeding during the entire hospital stay, ${ }^{22} 23$ associated with a postnatal weight loss less than $7 \%$ at 60 hours from birth. ${ }^{24}{ }^{25}$ Mother-baby dyads' socio-demographic, anamnestic, peripartum and breastfeeding data were collected by study investigators, as retrieved from their computerised medical charts.

\section{Sample size}

Personal data (Wetzl RG, A baby-friendly hospital, 2011) showed a ratio of 0.07 between women in the a priori choice group and those in the trying to cope group. Therefore, it was hypothesised that 208 women in the a priori choice group and 2975 women in the trying to cope group would be necessary to detect a $10 \%$ difference in BIS at discharge (from 0.55 to 0.45 ) ${ }^{26}$ At the end of the recruitment period, the power requirement for the planned endpoint of the study was wholly satisfied by the actual size of the enrolled population.

\section{Statistical analysis}

The descriptive data were presented as the number (n) and percentage for categorical variables, and as the mean, SD, median and the 10th and 90th percentiles for continuous variables. Bivariable associations between 
predictors, confounders and the endpoint were evaluated through the $\chi^{2}$ test using a two-tailed alpha of 0.05 and a power of 0.80 ( 1 - beta). Yates's correction for continuity was used when the expected value for at least one cell was less than 5 in a $2 \times 2$ contingency table.

The confounders that, according to the current literature, could be associated with BIS were entered into the analysis and grouped as antelabour-only and peripartum confounders. In addition to antelabour confounders, the peripartum confounders included the intrapartum and postpartum ones. To be considered an antelabour-only confounder, a factor was required to meet all the following criteria: (1) it must be present before labour initiation, that is, before exposure to analgesia; (2) there must be a theoretical basis for an association between the confounder and the endpoint; and (3) it should be impossible to reverse the temporal sequence. ${ }^{27}$ Online supplementary table A1 and 2 indicate the antelabour-only and peripartum confounders, and their diagnostic and categorising criteria.

In the analyses, if a categorical variable had three or more possible values, dummy variables were created. In most cases, previously published and validated cut-offs were used. If the percentile cut-off was used, the 10th and 90th percentiles were calculated for the entire population of women who delivered in the facility (Wetzl RG, Aosta whole birth cohort, 2016). To adjust for the risk estimates in the main effects, considering the dichotomous endpoint, a log-linear multivariable regression analysis was used and the confounders were entered using a forward selection procedure. $p<0.10$ was considered acceptable to enter the variable into the log-linear regression model. Prior to multivariable analyses, multicollinearity was assessed at each step of the analyses. Values of condition index $<15$, tolerance $>0.10$ and variance inflation factor $<10.0$ were considered acceptable. The accuracy of the log-linear regression model was assessed using Nagelkerke's $\mathrm{R}^{2}$ coefficient of determination. The results were reported as regression coefficient, relative risk (RR), 95\% CI, p value and risk difference (RD), as a measure of the absolute risk. Records with missing data were excluded from the multivariable log-linear analyses.

Data were analysed first on the whole population of recruited women (first-step) and then excluding women who underwent an unplanned caesarean section (second-step). At each step, data analyses were conducted following a two-stages design. For the first study hypothesis, BIS was compared between women in the trying to cope group and the a priori choice group. For the second study hypothesis, within the trying to cope group, BIS was evaluated by comparing women in the successful coping group with those in the last resort group. At each stage, multivariable analyses were performed in sequence, first with the antelabour-only confounders and then with the antelabour and peripartum confounders together.

Data were collected and tabulated using the FileMaker 11 Pro Relational Database (FileMaker, FileMaker
International, Santa Clara, California, USA). Statistical analyses were performed using SPSS V.22 (IBM SPSS Statistics).

\section{Patient and public involvement}

No parents were directly involved in setting the questions, selecting the outcome measure, designing and implementing the study. No parents were involved in the interpretation or writing up of study results.

\section{RESULTS}

The flow chart of the study steps has been presented in figure 1. From the set of eligible women $(n=3685)$, the following were excluded: 11 women with intrauterine fetal death, 40 single mothers and 6 women who requested but did not receive analgesia due to technical difficulties. Finally, for the first-step anlyses 3628 women were recruited (attempted vaginal birth population). For the second-step analyses, 445 women who underwent an unplanned caesarean section were excluded. Therefore, the population of actual vaginal birth comprised 3183 women.

No differences in basal characteristics were found between the women who were excluded from the study and those who were included (data not shown). Missing data values regarding the 50 considered confounders represented $0.003 \%$ of all the collected data, and deletion of the involved records did not impact the power requirements for the study endpoint.

\section{Descriptive analysis}

Tables 1-2 show the characteristics of the study's groups in the planned vaginal birth $(\mathrm{n}=3628)$ and actual vaginal birth population $(n=3183)$, respectively. Online supplementary tables A3-11 show the basal characteristics of the parents and newborns, the dyads' outcomes in caesarean and vaginal deliveries, and the basal and technical characteristics of administered neuraxial labour analgesia. The two groups of women who received neuraxial analgesia (whole cohort, $n=775$; a priori choice group, $n=207$; and last resort group, $\mathrm{n}=568$ ) showed no differences regarding the following variables: cervical dilation at the time of analgesia request, percentage of combined spinal-epidurals versus classic epidurals administered, number of administered boluses, cumulative opioid or local analgesic administered doses, and mother's satisfaction registered at least 24 hours after the birth (online supplementary table A7).

\section{Outcome data}

A significant reduction in BIS at discharge was found in both women who chose analgesia a priori (planned vaginal birth: trying to cope group vs a priori choice group, 2121/3421 (62.0\%; 95\% CI, $60.4 \%$ to $63.6 \%)$, vs $102 / 207$ ( $49.3 \%$; $95 \%$ CI, $42.5 \%$ to $56.1 \%$; p $<0.001$; $\mathrm{RD}=12.7 \%$ ); actual vaginal birth: trying to cope group vs a priori choice group, 1924/2994 (64.3\%; 95\% CI, 62.5\% 


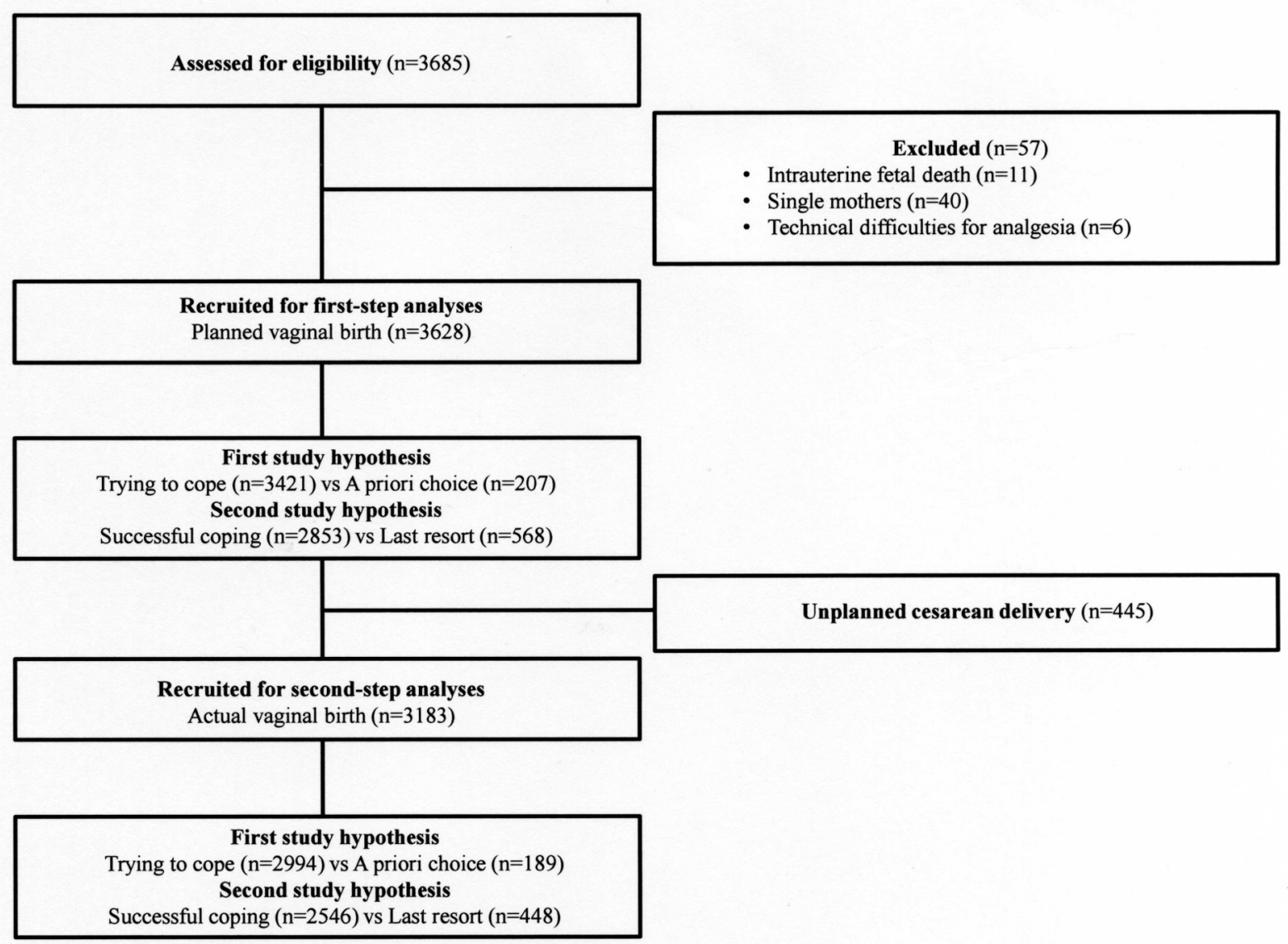

Figure 1 Flow chart of the study steps. For the first study hypothesis, among the women planning to give birth vaginally, breastfeeding initiation success (BIS) was compared between women who chose analgesia a priori and those trying to cope with labour pain. For the second study hypothesis, among the women who tried to cope with labour pain, BIS was compared between women who requested analgesia only as a last resort and those who coped with labour pain successfully.

to $66.0 \%)$, vs $93 / 189(49.2 \%$; $95 \% \mathrm{CI}, 42.1 \%$ to $56.3 \%$; $\mathrm{p}<0.001 ; \mathrm{RD}=15.1 \%)$ ), and women who requested analgesia as a last resort (planned vaginal birth: successful coping vs last resort group, 1804/2853 (63.2\%; 95\% CI, $61.5 \%$ to $65.0 \%$ ), vs $317 / 568$ (55.8\%; $95 \%$ CI, $51.7 \%$ to $59.9 \% ; \mathrm{p}=0.001 ; \mathrm{RD}=7.4 \%)$; actual vaginal birth: successful coping vs last resort group, 1665/2546 (65.4\%; $95 \% \mathrm{CI}, 63.5 \%$ to $67.2 \%)$, vs $259 / 448(57.8 \%$; $95 \% \mathrm{CI}$, $53.2 \%$ to $62.4 \%$; $\mathrm{p}=0.002 ; \mathrm{RD}=7.6 \%)$ ).

In the group of women trying to deliver vaginally, multivariable log-linear analyses with antelabour-only confounders showed that women who chose analgesia a priori had significantly less BIS than those who tried to cope with labour pain (planned vaginal birth: $R R=0.65$; $95 \% \mathrm{CI}, 0.48$ to $0.87 ; \mathrm{p}=0.004$; actual vaginal birth: $\mathrm{RR}=0.59 ; 95 \% \mathrm{CI}, 0.43$ to $0.80 ; \mathrm{p}=0.001$ ) (table 3 ).

In contrast, in the group of women trying to cope with labour pain, compared with those who succeeded in coping with labour pain, the group of women who requested analgesia as a last resort did not show an independent association with BIS according to multivariable log-linear analyses with either antelabour-only or antelabour and peripartum confounders considered together (planned vaginal birth: $\mathrm{RR}=0.99$; $95 \% \mathrm{CI}, 0.80$ to 1.23 ; $\mathrm{p}=0.955$; actual vaginal birth: $\mathrm{RR}=0.90 ; 95 \% \mathrm{CI}, 0.69$ to $1.16 ; p=0.405$ ) (table 4). On the contrary, being nulliparous or older, presenting with a higher body mass index or a greater pregnancy weight gain, or having delivered a newborn at a younger gestational age were associated with a decreased BIS at discharge.

\section{DISCUSSION}

The findings of the present study conducted in a babyfriendly hospital setting demonstrate that a woman's a priori choice of receiving neuraxial labour analgesia was independently associated with reduced BIS at discharge compared with women trying to cope with labour pain. In contrast, a woman's request for neuraxial labour analgesia as a last resort led to similar BIS as that among women who succeeded in coping with labour pain.

The first results of the present study could be partially explained hypothesising a greater motivational vulnerability towards breastfeeding among women choosing a priori to receive neuraxial labour analgesia as compared with women trying to cope with labour pain on their own, comprising also the group of women requesting neuraxial analgesia as a last resort. If this is true, women who choose 


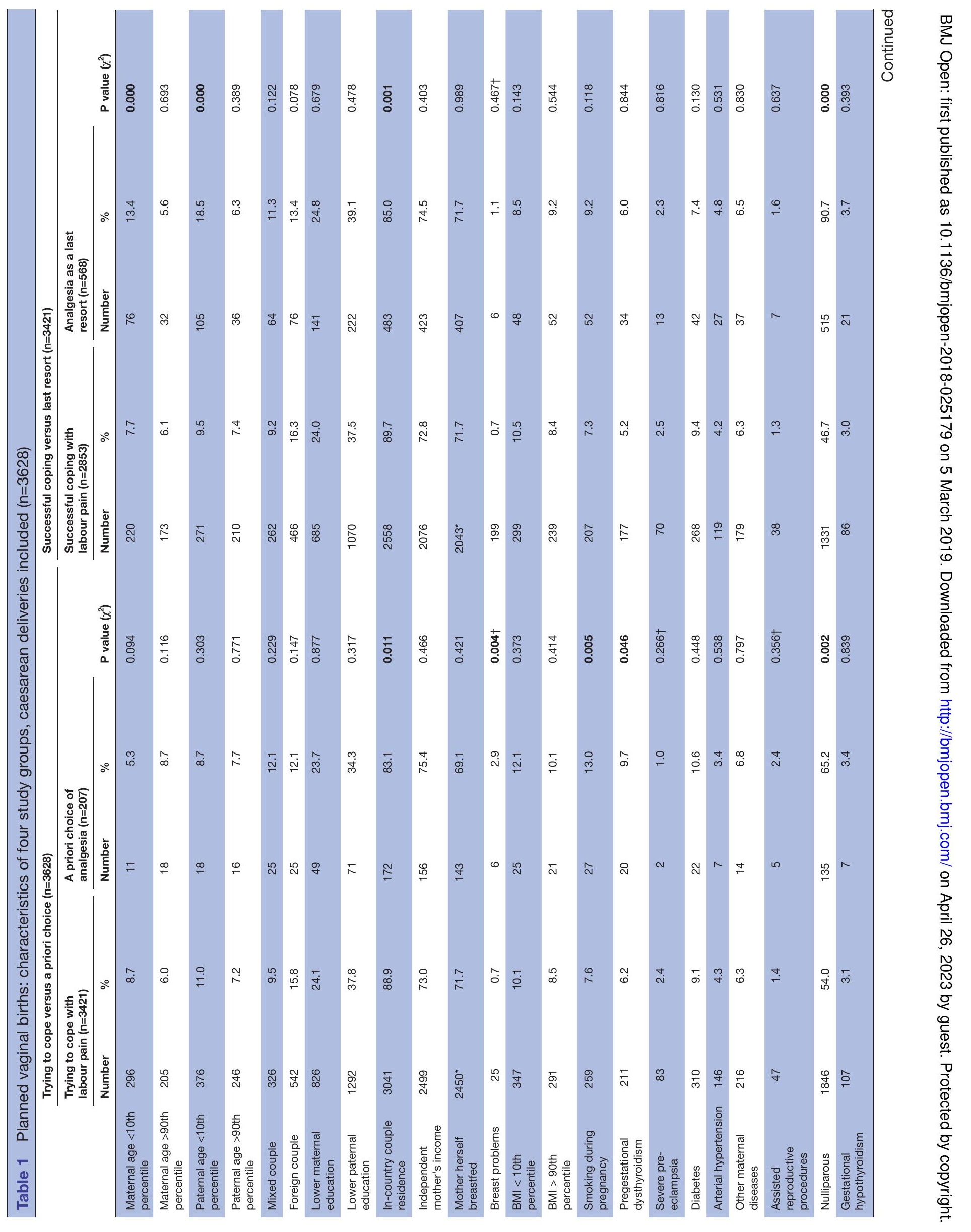




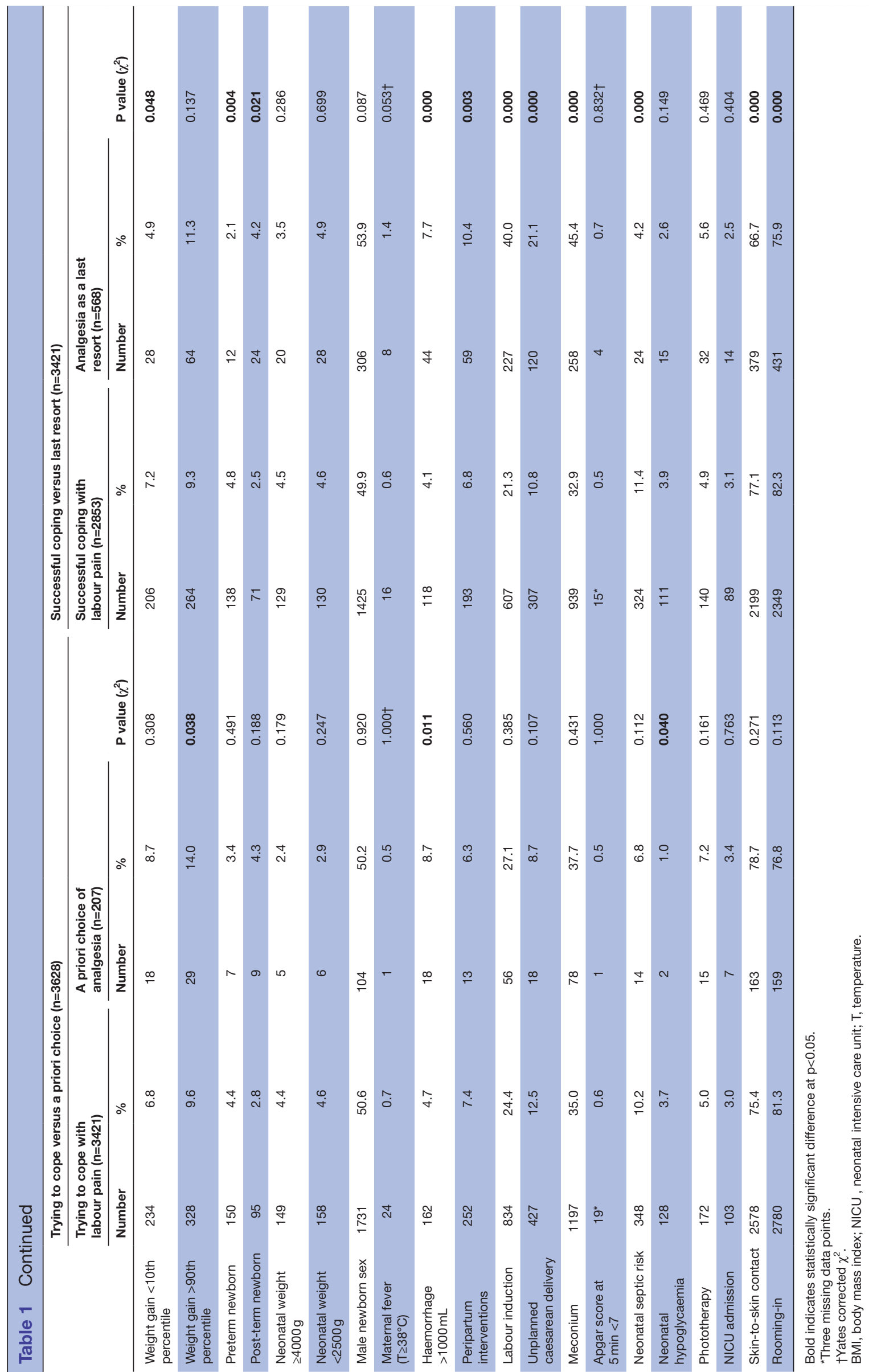

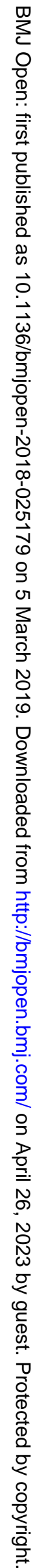




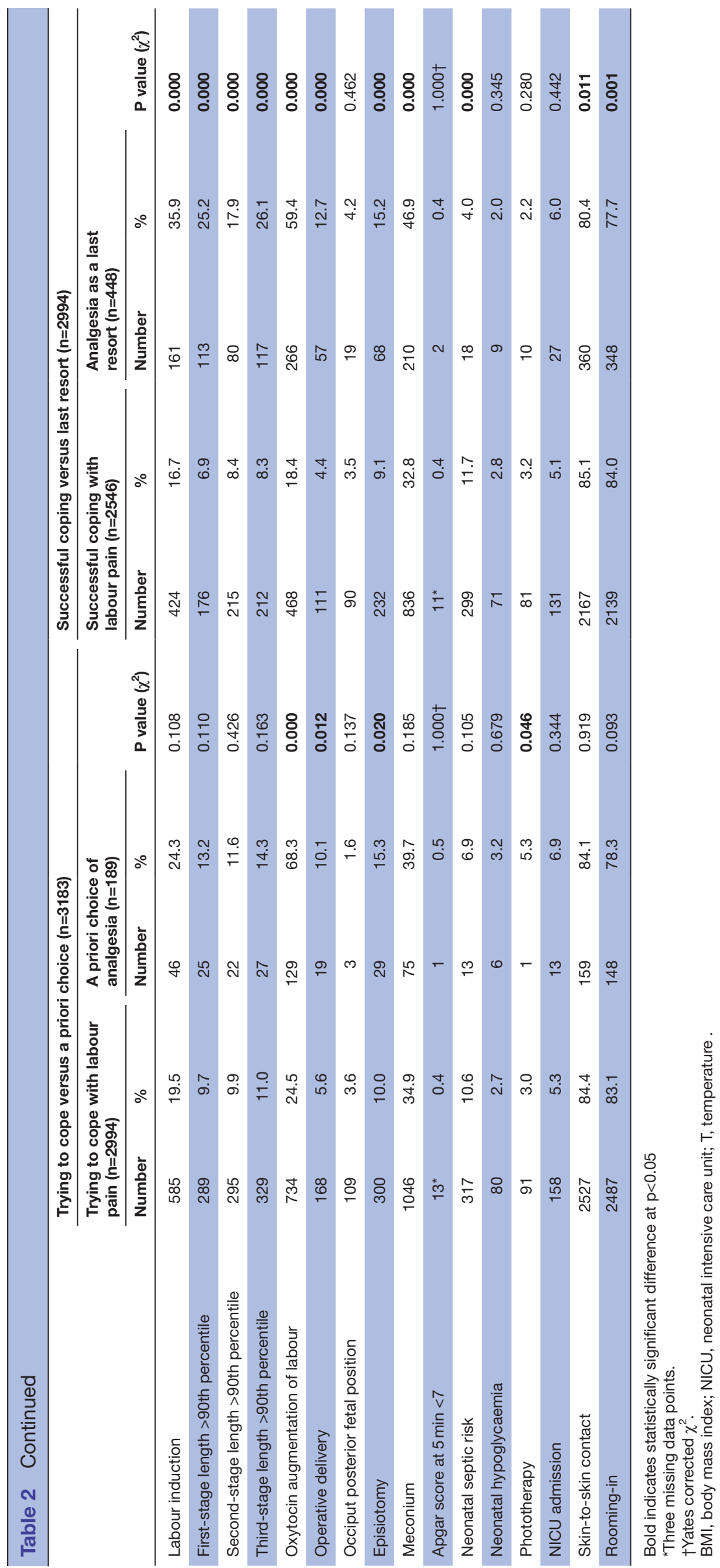

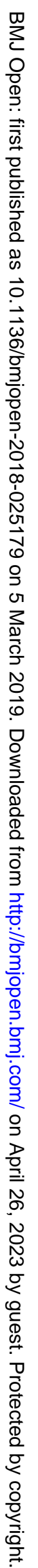




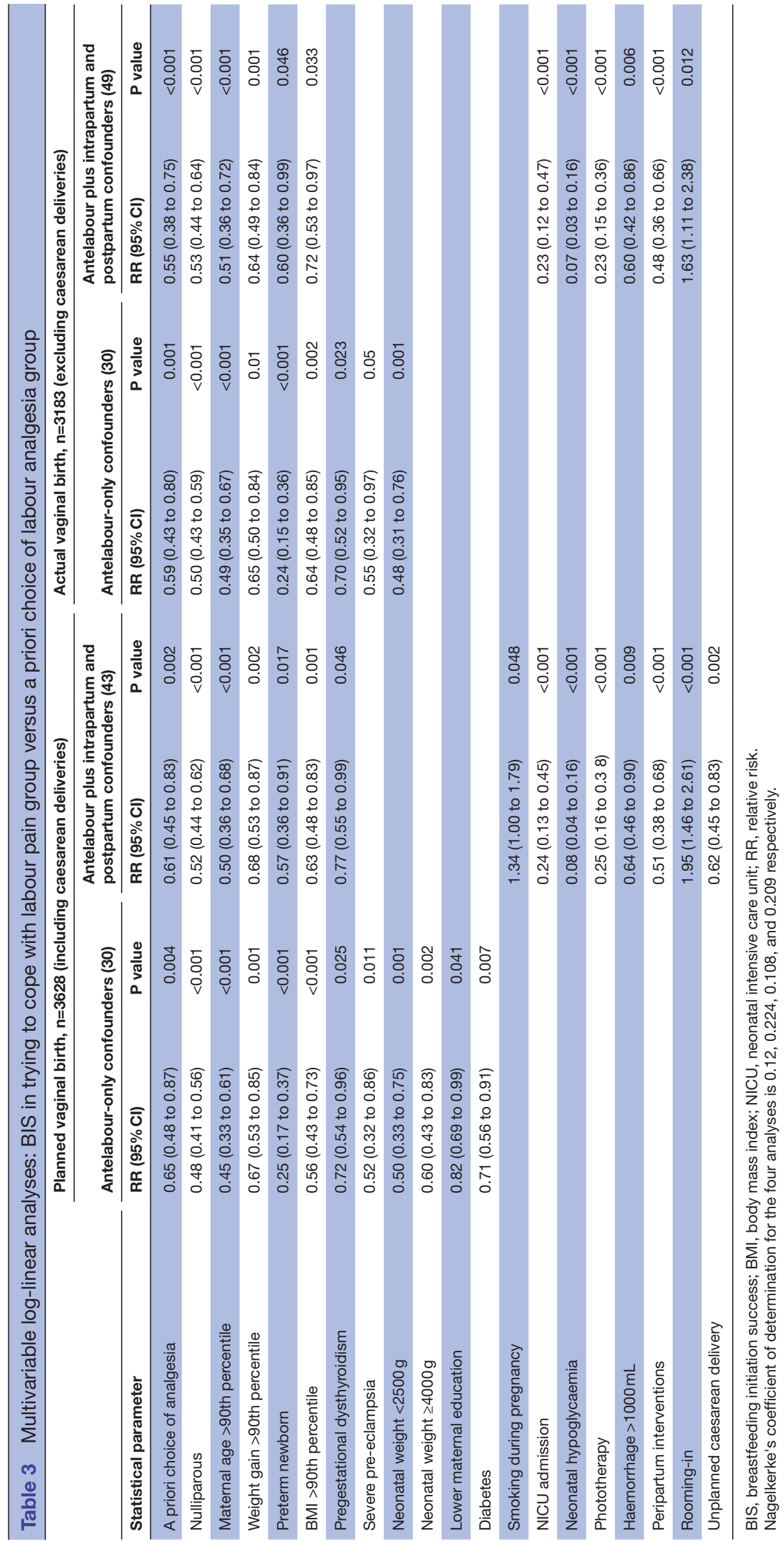




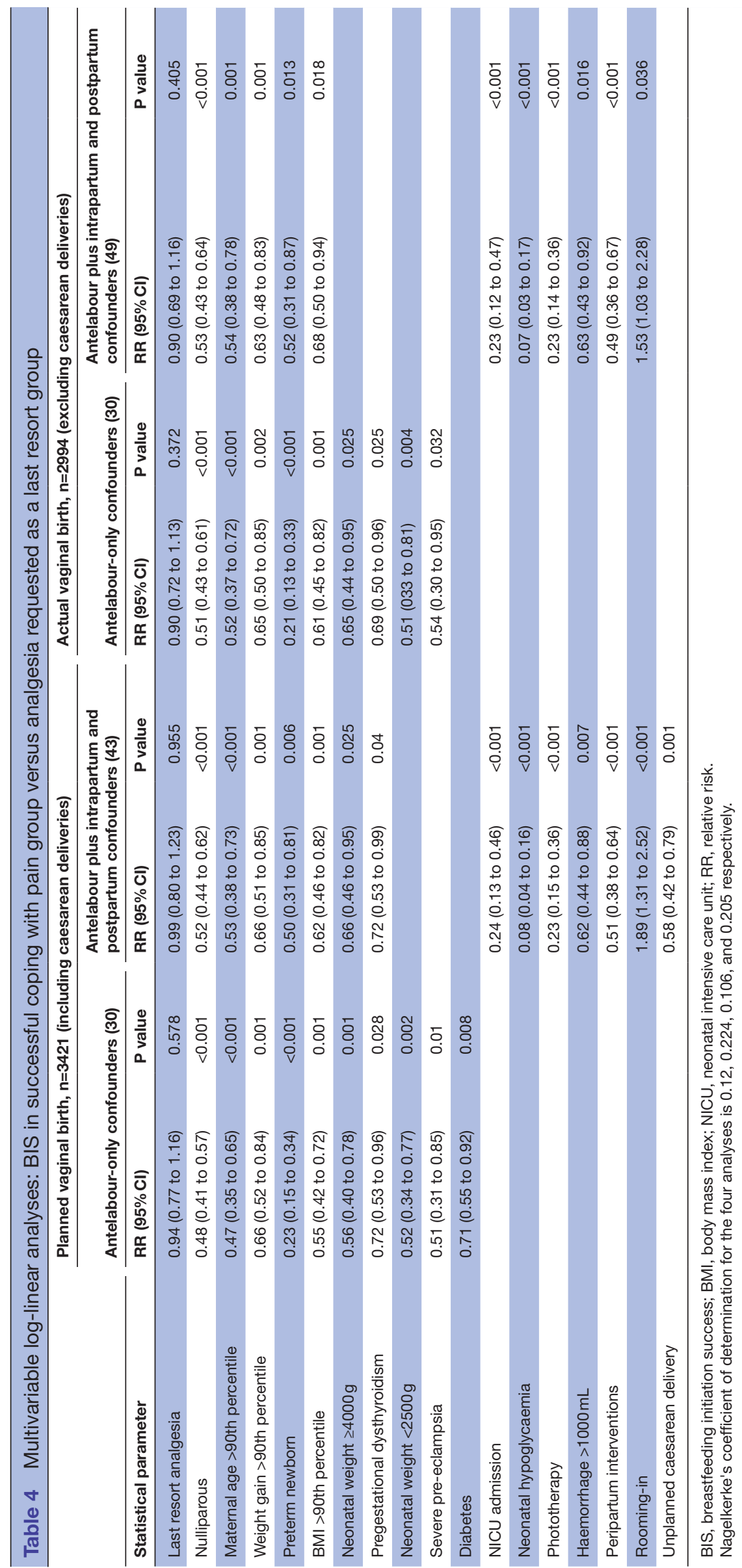

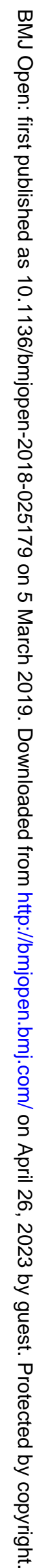


a priori to receive neuraxial labour analgesia would probably need increased peripartum breastfeeding support if they expressed the desire to breastfeed the baby. Although it cannot be ruled out that a mother's open externalisation of having chosen neuraxial labour analgesia a priori could simply represent a personal communicative style, we did not find studies addressing this topic. The second result of the present study could probably be explained hypothesising that, among the women trying to cope with labour pain, those requesting neuraxial analgesia as a last resort intrapartum received a medical intervention which at least seemed to not interfere with labour progression, probably because it was necessitated by actual or perceived difficulties of their own birth process. However, to the best of our knowledge, no previous study in literature has addressed this topic.

The findings of this study on the association of the wellknown peripartum confounders with the breastfeeding initiation process were consistent with those already emerging from the current literature, except those related to older maternal age. ${ }^{28-42}$ Regarding the association between older maternal age and breastfeeding, data in the current literature are conflicting. ${ }^{1743}$ Indeed, in the present study, the association between advanced maternal age and reduced breastfeeding success was confirmed by multivariable analyses because the sample included an almost unselected population of both nulliparous and multiparous women.

The effect of choosing to receive neuraxial labour analgesia on breastfeeding success remains a controversial issue. Previous studies reported breastfeeding initiation difficulties at hospital discharge in women who chose to receive neuraxial labour analgesia, ${ }^{12-16}$ with some studies even inferring a dose-response relationship between the dose of a particular opioid (usually fentanyl) and the proportion of mothers who showed breastfeeding initiation difficulties. ${ }^{1718}$ However, other studies did not report any association between the choice to receive neuraxial labour analgesia and breastfeeding initiation difficulties. ${ }^{43-55}$ The inconsistency of these findings is partially due to widespread deficiencies in study design. ${ }^{56}$ To the best of our knowledge, no study has considered breastfeeding success in women who chose to receive neuraxial analgesia, taking into account the nature of the request.

In addition to providing interesting clinical remarks, the present study has several limitations. First, we did not assess the coping styles of all the labouring women, including those who did not request analgesia at all, using the type of coping scale recently proposed by the American College of Obstetricians and Gynecologists. ${ }^{57}$ Second, the baby-friendly designation of the hospital where the study was conducted could have impacted the women's choice of the delivery setting, leading to a selection bias in the enrolled population. Some women could have chosen not to deliver in a baby-friendly hospital because they were afraid of feeling pressured into breastfeeding their newborn. On the other hand, some foreign women could have chosen to deliver their child in a baby-friendly hospital, which also offers free access to neuraxial labour analgesia at all times. To control for the latter selection bias, we included residence as a confounder in the multivariable analyses. Regarding the first bias, the percentage of women who resided in the valley and did not deliver at the study hospital was less than $3.9 \%$ of the whole obstetric population, including women who underwent a planned caesarean section (data retrieved from the regional health data register). Third, even though a randomised controlled trial is preferable when assessing the impact of a new treatment, the present study employed an observational design. Actually, should potential side-effects or adverse reactions of the administered drugs be investigated, a well-conducted observational study will not be irrelevant due to the particularly delicate ethical issues arising in obstetric or neonatology research. ${ }^{58}$ Fourth, the limitation stemming from the asynchrony in the time of collecting the choice of analgesia between the woman presenting in the active phase of labour and women undergoing labour induction needs to be acknowledged. Lastly, although a large number of peripartum variables were included in the multivariable analyses, the risk of residual confounding factors cannot be excluded.

In the statistical analyses we have not taken into account the technique used for administering neuraxial analgesia (spinal-epidural or classical epidural), since both techniques are major neuraxial blocks and are considered substantially equivalent, either in terms of analgesic efficacy, or of side effects, ${ }^{59}$ as underlined by the Cochrane Collaboration in a recent meta-analysis on the effects of neuraxial analgesia on the delivery's and newborn's outcomes. ${ }^{60}$

The generalisability of the present findings could be limited by its single-centre design. First, because the study was conducted in a baby-friendly hospital setting, we could have selected women with high motivation to breastfeed. Indeed, the any-breastfeeding proportion at discharge was $98.2 \%$, and the exclusive breastfeeding proportion was $82.9 \%$. Moreover, in the present study, the cumulative doses of the administered drugs were very low compared with those reported in the literature. ${ }^{6162}$ These low cumulative drug doses were due not only to technical choices adopted regarding the administered neuraxial analgesia but also to the intermittent on-demand pattern of drug administration by the duty anaesthetist and to the moderate level of pain control pursued according to women's wishes. However, these technical choices were consistent with the emerging tendency of offering a less aggressive neuraxial analgesia, as reported by the Cochrane Collaboration. ${ }^{60}$ Finally, regarding the drugs which were chosen for neuraxial analgesia, ropivacaine and sufentanil were administered as the local anaesthetic and opioid, respectively, while bupivacaine and fentanyl are used most frequently during delivery worldwide. Notwithstanding, the choice of sufentanil seems to be more appropriate in terms of fetal exposure. ${ }^{63}$

The present study also has a few strengths. First, the very limited number of exclusion criteria allowed us to recruit 
a population of mother-baby dyads that was not only large but also almost unselected. Only 57 women (1.5\%) were excluded from the whole cohort of 3685 women planning to give birth vaginally and willing to breastfed. Therefore, the present results seemed to be deeply contextualised in the actual complexity of a real birth setting in a babyfriendly hospital. Second, the two-stages design of the data analyses allowed us to use a large number of physiological deliveries as the true comparator. Indeed, $40.7 \%$ of the enrolled women delivered without any medical intervention. Lastly, in contrast to previous studies, the BIS definition included newborn weight loss at 60 hours from birth as an index of the newborn's nutritional status at discharge.

\section{CONCLUSIONS}

Based on the findings of the present study conducted in a baby-friendly hospital setting, the a priori choice of neuraxial labour analgesia is negatively associated with BIS as compared with women trying to cope with labour pain on their own. On the contrary, the decision to receive neuraxial labour analgesia as a last resort was not negatively associated with BIS as compared with women who coped with their pain successfully. Therefore, women who a priori choose to receive neuraxial labour analgesia and express the desire to breast feed the baby are to be considered at risk of breastfeeding initiation failure. Further studies are desirable to fully elucidate if these women can benefit from increased breastfeeding support and customised strategies implemented by health providers.

\section{Author affiliations}

${ }^{1}$ Department of Anaesthesia, Intensive Care, and Out-hospital Emergency, Ospedale Regionale della Valle d'Aosta, Aosta, Valle d'Aosta, Italy

${ }^{2}$ Mother-Child Department, Ospedale Regionale della Valle d'Aosta, Aosta, Valle d'Aosta, Italy

${ }^{3}$ Mother and Child Health Unit, Agenzia di Tutela della Salute della Città

Metropolitana di Milano, Milano, Italy

${ }^{4}$ Department of Clinical Sciences and Community Health, Fondazione IRCCS Cà Granda, Study University of Milan, Milano, Italy

Acknowledgements The authors would like to thank Alessandro Albani, who led the way in studying the relationship between neuraxial labour analgesia and breast feeding with the study he promoted in the 1990s at Parini Regional Hospital. The authors would also like to thank Loredana Tessarin, Stefania Fazari and the team of midwives; Marina Marmo, and the team of paediatrician nurses; Lina Levroux, Stefania Montinaro, Ilaria Del Sindaco and Simona Thoux, IBCLCs. Finally, the authors are grateful to all mothers and babies whom they have had the great pleasure of caring for at Parini Regional Hospital.

Contributors Study conceptualisation and design: RGW, ED, EBi, MEB, MLG and CA. Data collection instruments design and statistical data analyses: LP, MLG. Data acquisition: DG, GF and EBo (breastfeeding case notes), YV (antepartum anaesthesia examination case notes), FV (neonatal case notes), EBi (delivery room case notes) and SC (anaesthesia case notes). Data analysis and interpretation: RGW, ED, LP, YV, FV, SC, MEB, MLG, GF and EBo. Drafting of the manuscript: RGW, ED, YV, EBi, MLG and $\mathrm{EB} 0$. Revision of the draft for important intellectual content: LP, DG, FV, SC, MEB, GF and CA. Literature search: DG. All authors approved the final manuscript as submitted and agree to be accountable for all aspects of the work. RGW is the guarantor of the work as a whole, and affirms that the manuscript is an honest, accurate and transparent account of the study being reported; that no important aspects of the study have been omitted; and that any discrepancies from the study as planned (and, if relevant, registered) have been explained.
Funding The authors have not declared a specific grant for this research from any funding agency in the public, commercial or not-for-profit sectors.

Competing interests None declared.

Patient consent for publication Not required.

Ethics approval This study project was reviewed and approved by the Institutional Ethics Committee of Parini Regional Hospital, Aosta, Aosta Valley, Italy (register 166798).

Provenance and peer review Not commissioned; externally peer reviewed.

Data sharing statement The datasets used and/or analysed during the current study are available from the corresponding author on reasonable request.

Open access This is an open access article distributed in accordance with the Creative Commons Attribution Non Commercial (CC BY-NC 4.0) license, which permits others to distribute, remix, adapt, build upon this work non-commercially, and license their derivative works on different terms, provided the original work is properly cited, appropriate credit is given, any changes made indicated, and the use is non-commercial. See: http://creativecommons.org/licenses/by-nc/4.0/.

\section{REFERENCES}

1. Section on Breastfeeding. Breastfeeding and the use of human milk. Pediatrics 2012;129:e827-41.

2. Chowdhury R, Sinha B, Sankar MJ, et al. Breastfeeding and maternal health outcomes: a systematic review and meta-analysis. Acta Paediatr 2015;104:96-113.

3. Lodge CJ, Tan DJ, Lau MX, et al. Breastfeeding and asthma and allergies: a systematic review and meta-analysis. Acta Paediatr 2015;104:38-53.

4. Duijts L, Jaddoe VW, Hofman A, et al. Prolonged and exclusive breastfeeding reduces the risk of infectious diseases in infancy. Pediatrics 2010;126:e18-25.

5. Bowatte G, Tham R, Allen KJ, et al. Breastfeeding and childhood acute otitis media: a systematic review and meta-analysis. Acta Paediatr 2015;104:85-95.

6. Quigley MA, Kelly YJ, Sacker A. Breastfeeding and hospitalization for diarrheal and respiratory infection in the United Kingdom Millennium Cohort Study. Pediatrics 2007;119:e837-42.

7. Chantry CJ, Howard CR, Auinger P. Full breastfeeding duration and associated decrease in respiratory tract infection in US children. Pediatrics 2006;117:425-32.

8. Horta BL, Loret de Mola C, Victora CG. Long-term consequences of breastfeeding on cholesterol, obesity, systolic blood pressure and type 2 diabetes: a systematic review and meta-analysis. Acta Paediatr 2015;104:30-7.

9. Davanzo R, Copertino M, De Cunto A, et al. Antidepressant drugs and breastfeeding: a review of the literature. Breastfeed Med 2011;6:89-98.

10. Horta BL, Loret de Mola C, Victora CG. Breastfeeding and intelligence: a systematic review and meta-analysis. Acta Paediatr 2015;104:14-19.

11. Victora CG, Horta BL, Loret de Mola C, et al. Association between breastfeeding and intelligence, educational attainment, and income at 30 years of age: a prospective birth cohort study from Brazil. Lancet Glob Health 2015;3:e199-205.

12. Torvaldsen S, Roberts CL, Simpson JM, et al. Intrapartum epidural analgesia and breastfeeding: a prospective cohort study. Int Breastfeed J 2006;1:24-31.

13. Jordan S, Emery S, Watkins A, et al. Associations of drugs routinely given in labour with breastfeeding at 48 hours: analysis of the Cardiff Births Survey. BJOG 2009;116:1622-32.

14. Wiklund I, Norman M, Uvnäs-Moberg K, et al. Epidural analgesia: breast-feeding success and related factors. Midwifery 2009;25:e31-8

15. Gizzo S, Di Gangi S, Saccardi C, et al. Epidural analgesia during labor: impact on delivery outcome, neonatal well-being, and early breastfeeding. Breastfeed Med 2012;7:262-8.

16. Dozier AM, Howard CR, Brownell EA, et al. Labor epidural anesthesia, obstetric factors and breastfeeding cessation. Matern Child Health J 2013;17:689-98.

17. Jordan S, Emery S, Bradshaw $C$, et al. The impact of intrapartum analgesia on infant feeding. BJOG 2005;112:927-34.

18. Beilin $\mathrm{Y}$, Bodian CA, Weiser $\mathrm{J}$, et al. Effect of labor epidural analgesia with and without fentanyl on infant breast-feeding: a prospective, randomized, double-blind study. Anesthesiology 2005;103:1211-7.

19. Martin E, Vickers B, Landau R, et al. ABM clinical protocol \#28, peripartum analgesia and anesthesia for the breastfeeding mother. Breastfeed Med 2018;13:164-71. 
20. French CA, Cong X, Chung KS. Labor epidural analgesia and breastfeeding: a systematic review. J Hum Lact 2016;32:507-20.

21. World Health Organization. WHO recommendations: intrapartum care for a positive childbirth experience. Geneva: World Health Organization, 2018:83-92.

22. WHO/ UNICEF. Baby-friendly hospital initiative. revised, updated and expanded for integrated care. section i. background for implementation. Geneva, Switzerland: World Health Organization Document Production Services, 2009.

23. $\mathrm{WHO} / \mathrm{UNICEF}$. Baby-Friendly Hospital Initiative. Revised, updated and expanded for integrated care. section iii. breastfeeding promotion and support in a baby-friendly hospital. A 20-hour course for maternity staff. Geneva, Switzerland: World Health Organization Document Production Services, 2009.

24. Rosen AR, Lawrence RA. The effects of epidural anesthesia on infant feeding. J Univ Roch Med Ctr 1994;6:3-7.

25. Flaherman VJ, Schaefer EW, Kuzniewicz MW, et al. Early weight loss nomograms for exclusively breastfed newborns. Pediatrics 2015;135:e16-23.

26. Fleiss JL. Statistical methods for rates and proportions. 2nd ed. New York, NY: John Wiley and Sons Ltd, 1981.

27. Dewey KG, Nommsen-Rivers LA, Heinig MJ, et al. Risk factors for suboptimal infant breastfeeding behavior, delayed onset of lactation, and excess neonatal weight loss. Pediatrics 2003;112:607-19.

28. Fein SB, Roe B. The effect of work status on initiation and duration of breast-feeding. Am J Public Health 1998;88:1042-6.

29. Isabella PH, Isabella RA. Correlates of successful breastfeeding: a study of social and personal factors. J Hum Lact 1994;10:257-64.

30. Di Manno L, Macdonald JA, Knight T. The intergenerational continuity of breastfeeding intention, initiation, and duration: a systematic review. Birth 2015;42:5-15.

31. Schiff M, Algert CS, Ampt A, et al. The impact of cosmetic breast implants on breastfeeding: a systematic review and meta-analysis. Int Breastfeed J 2014;9:17-25.

32. Cruz NI, Korchin L. Breastfeeding after augmentation mammaplasty with saline implants. Ann Plast Surg 2010;64:1-3.

33. Arora S, McJunkin C, Wehrer J, et al. Major factors influencing breastfeeding rates: mother's perception of father's attitude and milk supply. Pediatrics 2000;106:e67.

34. Hackman NM, Schaefer EW, Beiler JS, et al. Breastfeeding outcome comparison by parity. Breastfeed Med 2015;10:156-62.

35. Meier PP, Furman LM, Degenhardt M. Increased lactation risk for late preterm infants and mothers: evidence and management strategies to protect breastfeeding. J Midwifery Womens Health 2007;52:579-87.

36. Lange A, Nautsch A, Weitmann K, et al. Breastfeeding motivation in pomerania: survey of neonates in pomerania (SNiP-Study). Int Breastfeed J 2016;12:3-10.

37. Haile ZT, Chavan BB, Teweldeberhan A, et al. Association between gestational weight gain and delayed onset of lactation: the moderating effects of race/ethnicity. Breastfeed Med 2017;12:79-85.

38. Amir LH, Donath S. A systematic review of maternal obesity and breastfeeding intention, initiation and duration. BMC Pregnancy Childbirth 2007;7:9-23.

39. Newby RM, Davies PS. Antenatal breastfeeding intention, confidence and comfort in obese and non-obese primiparous Australian women: associations with breastfeeding duration. Eur J Clin Nutr 2016;70:935-40.

40. Hauff LE, Leonard SA, Rasmussen KM. Associations of maternal obesity and psychosocial factors with breastfeeding intention, initiation, and duration. Am J Clin Nutr 2014;99:524-34.

41. Donath SM, Amir LH. Maternal obesity and initiation and duration of breastfeeding: data from the longitudinal study of Australian children. Matern Child Nutr 2008;4:163-70.
42. Cordero L, Valentine CJ, Samuels $P$, et al. Breastfeeding in women with severe preeclampsia. Breastfeed Med 2012;7:457-63.

43. Wilson MJ, MacArthur C, Cooper GM, et al. Epidural analgesia and breastfeeding: a randomised controlled trial of epidural techniques with and without fentanyl and a non-epidural comparison group. Anaesthesia 2010;65:145-53.

44. Albani A, Addamo P, Renghi A, et al. [The effect on breastfeeding rate of regional anesthesia technique for cesarean and vaginal childbirth]. Minerva Anestesiol 1999;65:625-30.

45. Halpern SH, Levine T, Wilson DB, et al. Effect of labor analgesia on breastfeeding success. Birth 1999;26:83-8.

46. Radzyminski S. The effect of ultra low dose epidural analgesia on newborn breastfeeding behaviors. J Obstet Gynecol Neonatal Nurs 2003;32:322-31.

47. Radzyminski S. Neurobehavioral functioning and breastfeeding behavior in the newborn. $J$ Obstet Gynecol Neonatal Nurs 2005;34:335-41.

48. Chang ZM, Heaman MI. Epidural analgesia during labor and delivery: effects on the initiation and continuation of effective breastfeeding. $J$ Hum Lact 2005;21:305-14.

49. Chen YM, Li Z, Wang AJ, et al. [Effect of labor analgesia with ropivacaine on the lactation of paturients]. Zhonghua Fu Chan Ke Za Zhi 2008;43:502-5.

50. Wang BP, Li QL, Hu YF. [Impact of epidural anesthesia during delivery on breast feeding]. Di Yi Jun Yi Da Xue Xue Bao 2005;25:114-5.

51. Bell AF, White-Traut R, Medoff-Cooper B. Neonatal neurobehavioral organization after exposure to maternal epidural analgesia in labor. $J$ Obstet Gynecol Neonatal Nurs 2010;39:178-90.

52. Wieczorek PM, Guest S, Balki M, et al. Breastfeeding success rate after vaginal delivery can be high despite the use of epidural fentanyl: an observational cohort study. Int J Obstet Anesth 2010;19:273-7.

53. Armani M, Gaggiano C, Dallaglio S, et al. Are there any strategies to improve neonatal outcomes associated with epidural analgesia in labor? Acta Biomed 2013;84:117-23.

54. Zuppa AA, Alighieri G, Riccardi R, et al. Epidural analgesia, neonatal care and breastfeeding. Ital J Pediatr 2014;40:82-7.

55. Lee Al, McCarthy RJ, Toledo P, et al. Epidural labor analgesiafentanyl dose and breastfeeding success: a randomized clinical trial. Anesthesiology 2017;127:614-24.

56. Szabo AL. Review article: Intrapartum neuraxial analgesia and breastfeeding outcomes: limitations of current knowledge. Anesth Analg 2013;116:399-405.

57. American College of Obstetricians and Gynecologists. Approaches to limit intervention during labor and birth. Committee Opinion No. 687. Obstet Gynecol 2017;129:e20-8.

58. Irl C, Hasford J. Assessing the safety of drugs in pregnancy: the role of prospective cohort studies. Drug Saf 2000;22:169-77.

59. Simmons SW, Taghizadeh N, Dennis AT, et al. Combined spinalepidural versus epidural analgesia in labour. Cochrane Database Syst Rev 2012;10:CD003401.

60. Anim-Somuah M, Smyth RM, Cyna AM, et al. Epidural versus nonepidural or no analgesia for pain management in labour. Cochrane Database Syst Rev 2018;5:CD000331.

61. Wilson MJ, Cooper G, MacArthur C, et al. Comparative Obstetric Mobile Epidural Trial (COMET) Study Group, UK. Randomized controlled trial comparing traditional with two 'mobile' epidural techniques: Anesthetic and analgesic efficacy. Anesthesiol 2002;97:1567-75.

62. Comparative Obstetric Mobile Epidural Trial (COMET) Study Group UK. Effect of low-dose mobile versus traditional epidural techniques on mode of delivery: a randomised controlled trial. Lancet 2001;358:19-23.

63. Loftus JR, Hill H, Cohen SE. Placental transfer and neonatal effects of epidural sufentanil and fentanyl administered with bupivacaine during labor. Anesthesiology 1995;83:300-8. 